\title{
Economics
}

The Open-Access, Open-Assessment E-Journal

Vol. 12, 2018-47 | July 26, 2018 | http://dx.doi.org/10.5018/economics-ejournal.ja.2018-47

\section{Policy experiments in an agent-based model with credit networks}

\author{
Tiziana Assenza, Alberto Cardaci, Domenico Delli Gatti, \\ and Jakob Grazzini
}

\begin{abstract}
In this paper the authors extend the macroeconomic agent-based model described in Delli Gatti, D., Desiderio, S., Gaffeo, E., Cirillo, P. and Gallegati, M. (Macroeconomics from the bottom-up, 2011) with the inclusion of a bank-bank network that mimics real-world dynamics of interbank markets. They also introduce a public sector and other modifications in order to carry out different policy experiments. More specifically, they test the implementation of a monetary policy by means of a standard Taylor rule, an unconventional monetary policy (i.e. helicopter drop) and a set of macroprudential regulations. The authors explore the properties of the model for such different scenarios. The results shed some light on the effectiveness of monetary and macroprudential policies in an economy with an interbank market during times of crises.
\end{abstract}

(Published in Special Issue Agent-based modelling and complexity economics)

JEL C63 E51 E52

Keywords Agent-based models; monetary policy; credit network

\section{Authors}

Tiziana Assenza, Complexity Lab in Economics (CLE), Università Cattolica del Sacro Cuore, Italy

Alberto Cardaci, Complexity Lab in Economics (CLE), Università Cattolica del Sacro Cuore, Italy, alberto.cardaci@unicatt.it

Domenico Delli Gatti, Complexity Lab in Economics (CLE), Università Cattolica del Sacro Cuore, Italy, and CESifo Group Munich, Germany

Jakob Grazzini, Complexity Lab in Economics (CLE), Università Cattolica del Sacro Cuore, Italy, and CESifo Group Munich, Germany

Citation Tiziana Assenza, Alberto Cardaci, Domenico Delli Gatti, and Jakob Grazzini (2018). Policy experiments in an agent-based model with credit networks. Economics: The Open-Access, Open-Assessment E-Journal, 12 (2018-47): 1-17. http:// dx.doi.org/10.5018/economics-ejournal.ja.2018-47

Received September 18, 2017 Published as Economics Discussion Paper September 25, 2017 Revised May 22, 2018 Accepted June 6, 2018 Published July 26, 2018

(c) Author(s) 2018. Licensed under the Creative Commons License - Attribution 4.0 International (CC BY 4.0) 


\section{Introduction}

In this paper we extend the macroeconomic agent-based model introduced in Macroeconomics from the Bottom Up (Delli Gatti et al., 2011) with the inclusion of a bank-bank credit network and other modifications - from the inclusion of the public sector, to a more detailed specification of the consumption function - with the ultimate goal of evaluating the impact of different policies in the presence of an interbank market. In fact, interbank markets represent one of the most important elements of the modern financial and monetary system (Allen et al., 2009). Well functioning interbank markets serve the purpose of enhancing liquidity exchanges among financial institutions as they facilitate the allocation of the liquidity surplus to illiquid banks, thereby playing a key role in banks liquidity management (Iori et al., 2015a; Xu et al., 2016). Interbank markets also are the focus of the implementation of monetary policies since they represent one of the main instruments for the transmission of monetary policy targets from central banks to the rest of the economy (Iori et al., 2015a). On the other hand, interbank markets are an important object of attention by regulators and policy makers due to their intrinsic network structure that may amplify the response of the financial system to (even single seemingly isolated) shocks, thus paving the way for potential financial contagion and domino effects (Ferrari, 2016).

In the light of these considerations, we build a theoretical framework that enables us to analyse the effectiveness of different types of policies in times of crisis, with a particular focus on the functioning of the interbank market. The model allows to replicate different scenarios. In particular, we analyse the implications of a fixed nominal interest rate, which leaves no space for intervention on behalf of the central bank. Eventually, in a different scenario, we introduce a central bank operating via a standard Taylor Rule (Taylor, 1993) that targets inflation. We then test the introduction of an unconventional monetary policy of the helicopter money type (Friedman, 1969), which is implemented by providing households with an amount of liquid assets that can be potentially used for consumption purposes.

Our framework also allows for the analysis of different types of macroprudential policies thus contributing to the hotly debated issue of macroprudential regulation (Hanson et al., 2011; Shin, 2011). More specifically, we act on two factors, representing the maximum bank leverage and the required liquidity ratio, in order to assess whether different regulatory scenarios significantly change the dynamics of the system in terms of stability and emergence of financial crises.

To give a preview of our results, in all the simulations a number of crises of different intensity and duration emerges in our artificial economy. However, the system performs better under the Taylor rule as the economy shows a lower number of recessionary episodes, as well as a shorter duration of the periods of crisis, compared to the other two types of monetary policy that we simulate. Additionally, the most effective macroprudential policy in our framework is the one that targets the maximum leverage ratio of the banking sector. Indeed, when policy authorities act on this variable, the frequency of the crises is lower with respect to the simulations in which policy authorities act on the required liquidity ratio. 


\subsection{Literature review}

Typical aspects that have been explored by the literature on interbank markets have to do with the inefficiencies related to the incompleteness of interbank markets (e.g. Allen and Gale 2000; Allen et al., 2009; Freixas et al., 2011), asymmetric information (Heider et al., 2015) or monopoly power (Acharya and Yorulmazer, 2008). Other works focus on the network formation mechanism behind the emergence of interbank markets (Xu et al., 2016) or the study of the relationship between bank characteristics and the distribution of funding spreads observed in the interbank money markets (Iori et al., 2015b). Finally, several models of the interbank market tend to analyse monetary policy issues in isolation rather than in a fully specified macroeconomic model (e.g. Freixas and Jorge, 2008; Freixas et al., 2011). Indeed, only a few studies have considered the presence of possible links between the macro-economy and the financial sector via interbank markets. For example, Delli Gatti et al. (2009) build an artificial network of a macro-economy characterised by firm-firm and bank-firm credit relationships, which is meant to study the endogenous formation of business cycles as a consequence of the complex interaction of the heterogeneous financial conditions of the agents involved. Another example is the work by Tedeschi et al. (2012), who develop an interbank system within a three-sector agent-based model aimed at studying the correlation between bankruptcy cascades and the endogenous economic cycle of booms and busts. These studies, however, do not focus on the role of monetary policy and its relationship with the interbank market and the macro-economy. On the contrary, our work contributes to the existing literature by investigating the effectiveness of different types of monetary policies. Also Gabbi et al. (2015) build a macro ABM that focuses on the linkage between the interbank market and the real economy with a stylised central bank which acts as a lender of last resort. However, a key aspect that differentiate this model from the one described in this paper is the study of both conventional and unconventional monetary policies. Indeed, even though the analysis of monetary policy represents a major focus both in the standard macroeconomic literature (see, for example, Christiano et al., 2005; Smets and Wouters, 2007) and in the macro agent-based literature (e.g. Delli and Desiderio (2015); Gualdi et al., 2017), few works have investigated the implications of the unconventional types of policies. In fact, as argued in the work by Gertler and Karadi (2011), most of the contributions that have tried to study this issue have been mainly qualitative as opposed to quantitative (e.g. Kiyotaki and Moore, 2012; Adrian and Shin, 2009). As a matter of fact, in the same work, Gertler and Karadi build a DSGE model in order to analyse the effects of the central bank using unconventional monetary policy to stimulate the economy during a financial crisis. However, the type of unconventional policy that they replicate in their environment is one which allows the central bank to act as intermediary in the credit market by borrowing funds from savers and then lending them to investors. As such, this is a different approach compared to the one implemented in our framework, where the central bank simply operates as the metaphorical helicopter evoked by (Friedman, 1969), which drops free money in the hands of the households. As pointed out by Michaillat and Saez (2014), money in this case may be issued by buying bonds through open market operations or it may be simply printed and given directly to households through the helicopter drop. The approach adopted in our model follows the latter. 
The paper is organized as follows. Section 2 introduces the main elements of novelty of our model. Section 3 describes the main results of our computer simulations. Finally, Section 4 concludes.

\section{The environment}

In general, the basic set-up of our model replicates the one reported in Delli Gatti et al.(2011), with the inclusion of a credit network of the bank-bank type. Our artificial economy is populated by heterogeneous households, divided in three classes: workers, capitalists and bankers. The model also features heterogeneous firms and banks. In each period $t$ the following sequence events takes place:

1. Firms make quantity and price decisions. They also set their labour demand based on production needs.

2. The government pays interest on the bonds.

3. The credit market opens: firms receive credit from the banking sector.

4. The job market opens: firms with excess workers fire their employees, while those who need to increase their workforce hire new individuals. After the market closes, wages are paid.

5. Fiscal policy decisions: taxes are collected and desired government spending is set. The government also sets bond supply.

6. The bond market opens: firms provide the government with funding.

7. The goods market opens: both households and the government buy goods from the firms.

8. Firm and bank dividends are paid to capitalists and bankers respectively.

9. The interbank market opens: banks carry out borrowing and lending operations.

10. Monetary policy decisions: the central bank sets the policy interest rate.

In the following sections, we will briefly describe the salient features of the interbank market, while eventually focusing on the other elements of novelty introduced by the other extensions to the original framework. In particular, these include the introduction of a class of bankers; the modification of the consumption function; the introduction of some elements of friction in the labour market; the presence of a public sector with a government that issues bonds and a central bank that operates under a Taylor Rule. Let us analyse each of the aspects individually. 


\subsection{Banks and the interbank market}

The set of heuristics and behaviours of the heterogeneous banks in our model is tightly in line with the ones reported in the original model by Delli Gatti et al.(2011),. The main element of novelty regarding this sector is the extension to a bank-bank network that replicates the essential features of real-world interbank markets. Figure 1 provides an illustrative representation of the firm-bank and the newly introduced bank-bank network present in our model.

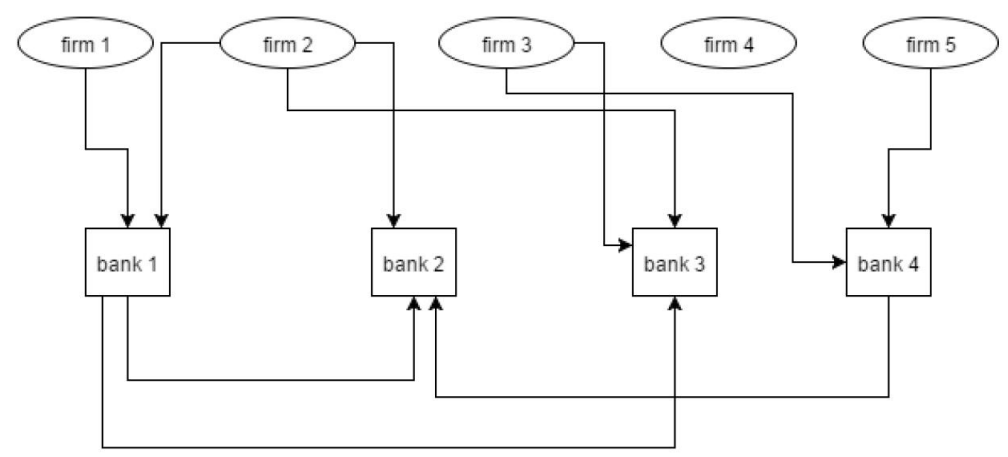

Figure 1: Representation of the firm-bank and bank-bank network in our model. The links represents credit contracts.

The presence of the interbank market in the model is motivated by the introduction of a required liquidity ratio whose value serves as a threshold that establishes whether a commercial bank is in need of liquidity. In fact, there exists the possibility that banks run out of the liquid resources that are needed to meet regulatory requirements. Indeed, in this case, banks with insufficient liquidity apply for a loan from banks with excess liquidity.

Let us start our description of the functioning of the interbank market with an outline of the balance sheet position of generic bank $b$ at the end of each period. In normal times, such bank has already reimbursed interbank loans (if it happened to be borrower on the interbank market) or it has been reimbursed (if a lender). Therefore its liquidity is:

$$
M_{b, t}=\mathscr{M}_{b, t}+E_{b, t}-D_{t}^{b}
$$

where $\mathscr{M}_{b, t}$ represents deposits by households and firms, $E_{b, t}$ is the bank's equity and $D_{t}^{b}$ is the amount of loans to the production sector.

A key indicator for banks is the current liquidity ratio, which is introduced in the model as follows:

$$
m_{b, t}=\frac{M_{b, t}}{\mathscr{M}_{b, t}}
$$

Banks compare the value of such ratio with the required value set by regulators. This is the minimum ratio $\left(\bar{m}_{b}\right)$ of liquidity to deposits which must be satisfied by all banks at the end of each period. Specifically, the liquidity requirement is satisfied if $m_{b, t} \geq \bar{m}_{b}$. Banks with $m_{b, t}<\bar{m}_{b}$ violate the liquidity requirement and apply for a loan on the interbank market. 
The net demand for interbank loans by the generic bank $b$ is defined as:

$$
\Lambda_{b, t}=\left(\bar{m}_{b}-m_{b, t}\right) \mathscr{M}_{b, t}
$$

If $m_{b, t}<\bar{m}_{b}$ then $\Lambda_{b, t}>0$, so that the bank has a positive demand for liquidity. If, on the contrary, $m_{b, t}>\bar{m}_{b}$ then $\Lambda_{b, t}<0$, which implies that the bank has excess liquidity. Specifically, its excess liquidity is given by $\Delta M_{b, t}=\left(m_{b, t}-\bar{m}_{b}\right) \mathscr{M}_{b, t}$.

Notice that excess liquidity is a necessary but not sufficient condition for a bank to supply loans in the interbank market. Indeed, in order to be a lender in the interbank market, a bank must meet not only the liquidity requirement but also the capital requirement since loans in the interbank market enter the equity ratio of the bank. The presence of a capital requirement implies that the banks in our model have to comply with a prudential regulation, in line with the regulatory framework introduced by Basel III (Basel Committee on Banking Supervision, 2011).

The capital requirement coefficient contributes to determine the maximum maximum amount of loans that a bank can supply in the interbank market, which is defined as follows:

$$
\hat{\Lambda}_{t}^{b}=E_{b, t} \bar{\lambda}_{b}-D_{t}^{b}
$$

where $\lambda_{b}$ is the capital requirement coefficient, which represents a cap on the bank leverage. Eventually, the actual supply of interbank loans by bank $b$ is as follows:

$$
\Lambda_{t}^{b}=\min \left(\hat{\Lambda}_{t}^{b}, \Delta M_{b, t}\right)
$$

This is defined as the minimum between the maximum loan that may be supplied in accordance with the capital requirement (i.e. $\hat{\Lambda}_{t}^{b}$ ) and the maximum loan that satisfies the liquidity requirement, that is $\Delta M_{b, t}$.

Transactions in the interbank market occur based on a random matching process that runs up until all lenders have been visited, or until all borrowers have obtained the desired amount of loans. This implies that a bank-bank credit network emerges endogenously in each period. Indeed, since interbank loans are 1-period contracts, the structure of the network changes at every period $t$ based on developments in other markets that modify the liquidity needs of the banks.

A final element of novelty regarding the banking sector is represented by the introduction of a class of bankers. Each of the bankers is assumed to own one bank and, as such, benefits from the distribution of dividends. In particular, each bank retains a portion $\left(1-\phi_{b}\right)$ of its profits, while distributing a share $\left(\phi_{b}\right)$ to the corresponding owner.

\subsection{Labour market}

The labour market features two main elements of novelty compared Delli Gatti et al.(2011). First, workers earn a homogeneous wage $\left(w_{t}\right)$ that is determined endogenously in the labour market in every period. Such wage is a function of unemployment: in particular, at each time $t$, the workers' 
wage in the previous period is updated based on a sensitivity factor $(\xi)$ that multiplies the difference between the threshold level of unemployment $(U)$ and the current value of unemployment $\left(U_{t}\right)$. Notice that both $\xi$ and $U$ are two factors that are assumed to depend on the structural properties of the labour market.

$$
w_{t}=w_{t-1}\left(1+\xi\left(U-U_{t}\right)\right)
$$

Therefore, Equation 6 implies that the higher the difference between $U$ and $U_{t}$, the higher the current wage at time $t$. As such, the wage equation models the negative correlation between unemployment and wage inflation thereby mimicking the main mechanism behind the Phillips Curve (Phillips, 1958).

The second new aspect introduced in the labour market deals with the presence of an element of friction in the search and matching mechanism. Indeed, real world markets are characterised by frictions that are typically due to heterogeneity and imperfect information about potential partners, which explain the departure from the competitive paradigm (Krause et al., 2014). In this spirit, we assume that the matching process in our framework does not occur automatically. Rather, there is a probability associated with it, so that unemployed workers who find a vacancy may have to keep on looking for one if the matching does not occur at the first try. One could interpret this structure as a matter of luck. After all, "being unemployed contains a measure of bad luck: The individual in question simply was not matched to a willing employer for reasons that an outside observer cannot ascertain" (Krause et al., 2014, p.19).

\subsection{Consumption function}

We assume the existence of two different consumption regimes. One applies to workers who consume out of disposable income and liquid wealth; the other regime applies to capitalists and bankers who, instead, consume out of wealth only.

Equation 7 identifies the individual consumption of workers $\left(C_{t, h}\right)$.

$$
C_{t, h}=c_{y}(1-\tau) w_{t}+\max \left[c_{w}-\phi_{r} R_{t}, 0\right] D_{t-1, h}
$$

$\tau$ identifies the exogenous tax rate on income so that disposable income is defined as $(1-\tau) w_{t}$, while $D_{t-1, h}$ is the amount of deposits inherited from the previous period. $c_{y}$ is the propensity to consume out of disposable income and $c_{w}$ is the propensity to consume out of deposits, which is negatively affected by the level of the real interest rate $\left(R_{t}\right)$ multiplied by a sensitivity parameter $\left(\phi_{r}\right)$.

Capitalists and bankers earn dividends from firms and banks respectively. As already pointed out, we assume that these two classes of individuals are subject to a different kind of consumption regime in that their decision depends exclusively on the individual level of wealth. Indeed, Equation 8 describes the individual consumption of such agents as a function of their deposits.

$$
C_{t, h}=\max \left[c_{w}-\phi_{r} R_{t}, 0\right] D_{t-1, h} \quad \forall h=\text { capitalist } \text { or banker }
$$


Similar to workers, also capitalists and bankers' decision is affected by the level of the real interest rate. The motivation behind such peculiar design lies in decision to introduce a key role for the interest rate in the trade-off between consumption and saving decisions. Indeed, since all agents receive interest on their deposits, a higher level of the interest rate is supposed to lower the amount of resources that are used for consumption purpose, while increasing the amount that is going to be saved and deposited at a bank.

\subsection{Public sector}

The model features a public sector composed by a government and a central bank. In general, the introduction of the public sector is motivated by the need to extend the macroeconomic structure of the model in order study the implications of different types of regulatory policies, with a particular focus on conventional and unconventional monetary policies.

The government acts as a buyer in the goods market and, as such, it sets a desired level of public spending $\left(G_{t}^{d}\right)$ as described in Equation 9. The evolution of the desired public spending is related to the level of public debt relative to GDP, as we assume that the government has to meet a specific target ratio. In particular, $G_{t}^{d}$ equals its value in the previous period multiplied by a positive scaling factor $\left(\phi_{t}^{G}\right)$, if the public debt-to-GDP ratio in the previous period $\left(P D_{t-1}\right)$ is less or equal to its target value $(\overline{P D})$. On the contrary, if $P D_{t-1}>\overline{P D}$, the government scales down its desired public spending from the previous period by the same term $\phi_{t}^{G}$.

$$
G_{t}^{d}= \begin{cases}G_{t-1}^{d}\left(1+\phi_{t}^{G}\right) & \text { if } P D_{t-1} \leq \overline{P D} \\ \max \left[G_{t-1}^{d}\left(1-\phi_{t}^{G}\right), 0\right] & \text { if } P D_{t-1}>\overline{P D}\end{cases}
$$

Notice that the scaling factor $\phi_{t}^{G}$ is a function of the relative distance $\left(\varepsilon_{t}\right)$ between the actual value of the public debt-to-GDP ratio and its target level. In particular, the larger such distance, the greater the value of $\phi_{t}^{G}$ and, as a consequence, the stronger the adjustment in the level of desired public spending. Additionally, $\phi_{t}^{G}$ oscillates within two exogenously set boundaries $\left(\phi_{\min }^{G}\right.$ and $\left.\phi_{\max }^{G}\right)$.

$$
\begin{aligned}
& \phi_{t}^{G}=\phi_{\min }^{G}+\frac{\phi_{\max }^{G}-\phi_{\min }^{G}}{1+\frac{1}{\left|\varepsilon_{t}\right|}} \\
& \varepsilon_{t}=\frac{P D_{t}-\overline{P D}}{\overline{P D}}
\end{aligned}
$$

The government collects taxes on income based on the exogenous tax rate introduced above. If the amount of collected taxes is not enough to finance desired government spending and the repayment schedule on public debt, the government enters the bond market to find the necessary external finance. As such, bond supply $\left(B S_{t}\right)$ in each period equals the sum of desired government spending $\left(G_{t}^{d}\right)$ and the balanced owed on the existing public debt $\left(r e p_{t}\right)$, net of tax revenues $\left(T_{t}\right)$.

$$
B S_{t}=\max \left[G_{t}^{d}+r e p_{t}-T_{t}, 0\right]
$$


The demand side in the bonds market features banks. In particular, for simplicity, we assume that banks want to convert a fixed share of their liquidity into bonds. The functioning of the market is based on a simple search and match mechanism, characterised by a randomisation of the order of interactions between banks and the government. The last banks that interact with the government obtain the desired amount of bonds - thus providing the desired amount of funds - as long as the bond supply is still positive. As such, some banks may be rationed in the bond market. On the other hand, in case the market is short of demand, the central bank can operate as a lender of last resort. This indeed occurs only when all the commercial banks have obtained the desired amount of bonds and the residual government supply is still positive.

Bonds correspond to a multi-period repayment schedule for the government. For simplicity we also assume that the interest rate on bonds equals the nominal interest rate set by the central bank.

As already specified, the model replicates different types of scenarios depending on the type of monetary (and regulatory) policy that is implemented. In general, the central bank operates by setting a nominal interest rate that is constant over time. This is the baseline version of the model. However, in a different scenario, the central can operate through a standard Taylor Rule, thus determining the nominal interest rate $\left(i_{t}\right)$ as a function of the target interest rate $(\bar{i})$, the actual interest rate in the previous period and the inflation gap. The latter is equal to the difference between the current inflation rate $\left(\pi_{t}\right)$ and the its target level $(\bar{\pi})$. As shown in Equation 13, these factors are multiplied by three sensitivity parameters, respectively $\alpha_{1}, \alpha_{2}$ and $\phi_{p}$.

$$
i_{t}=\alpha_{1} \bar{i}+\alpha_{2} i_{t-1}+\phi_{p}\left(\pi_{t}-\bar{\pi}\right)
$$

Also notice that the central bank has a minimum and maximum nominal interest rate that define the limits of oscillation of the actual interest rate, so that $i_{t} \in\left[i_{\min }, i_{\max }\right]$, where $i_{\min }$ and $i_{\max }$ are exogenous parameters.

\section{Simulations}

We investigate the macro and micro features of the model described in this paper by means of computer simulations, which are implemented through Monte Carlo (MC) repetitions with 50 different random seeds in each scenario. Eventually we compute the cross-simulation mean of the key variables for each scenario. Overall, the model runs for 10000 periods representing one week each. Results are eventually represented and discussed in quarters. Moreover, in all the simulations we drop the first 100 periods in order to get rid of transients.

All the simulations are implemented under the parameter vector reported in Table 1.

At this stage we do not want to replicate any empirical regularities, rather the choice of the parameter vector is based on the need to rule explosive dynamics and unrealistic patterns.

We proceed as follows: first, we analyse model dynamics in the baseline scenario, thereby discussing the main factors that drive the system on the brink of a crisis. Eventually, we are going to compare the different policy implementations introduced in the other scenarios. 


\begin{tabular}{ccc}
\hline \hline Parameter & Description & Value \\
\hline$c_{y}$ & Propensity to consume out of income & 0.9 \\
$c_{w}$ & Propensity to consume out of wealth & 0.2 \\
$\tau$ & Tax rate & 0.05 \\
$\bar{m}_{b}$ & Minimum liquidity ratio & 0.1 \\
$\bar{\lambda}_{b}$ & Capital requirement coefficient & 10 \\
$\phi_{r}$ & Consumption sensitivity to the interest rate & 0.05 \\
$\xi$ & Wage sensitivity to unemployment & 0.001 \\
$\alpha_{1}$ & Taylor rule sensitivity to target interest rate & 0.1 \\
$\alpha_{2}$ & Taylor rule sensitivity to past interest rate & 0.9 \\
$\phi_{p}$ & Taylor rule sensitivity to inflation gap & 0.01 \\
$\bar{\pi}$ & Target inflation rate & 0.02 \\
\hline \hline
\end{tabular}

Table 1: Model calibration.

The baseline scenario consists in the simulation of the model under the calibration specified above. In this case, however, the Taylor Rule is not active, so that the central bank fixes a constant nominal interest rate equal to $2 \%$.

Baseline results indicate that our extensions to Delli Gatti et al. (2011) play a major role in affecting model dynamics. In particular, we notice that MC simulations produce a rather stable trend characterised by low volatility across simulations until approximately period 250: production evolves with an irregular pattern characterised by minor oscillations along a constant trend (Figure 2 , top). However, volatility across simulations is higher in the following periods, indicating the emergence of some booms and bust at the level of single-seed simulations. Indeed, these show the emergence of a series of large endogenous crises. For example, Figure 2 (bottom) reports the time series of production for a single simulation: the graph shows the presence of two large crisis episodes (roughly around period 500 and 700).

The amount of credit being issued by the banking sector also experiences a contraction during the period of crisis, as shown in the top panel in Figure 3. It is also worth pointing out the active role of the interbank market across simulations. In particular, banks seem to interact with each other in the interbank market especially right before the crisis and during the turning point at the end of the recession, when the amount of loans exchanged in the interbank market peaks at roughly more than 700 (Figure 3, bottom panel).

Some other interesting dynamics take place in the banking sector. Figure 4 shows the evolution over time of the equity of each bank $b$. There are two relevant aspects. First, the banking sector experiences the default of 14 out of 20 banks before the emergence of the major crisis at around period 400. In particular one of the big banks (in terms of equity) goes bankrupt slightly before the beginning of the crisis. This phenomenon may be partly responsible for the decline in total credit and the exacerbation of the crisis. In a way, our finding identifies the pivotal role of some banks in driving model dynamics to the crisis. By adopting the terminology by the (Financial Stability Board, 2011), such banks in our model may be defined as Systemically important financial 

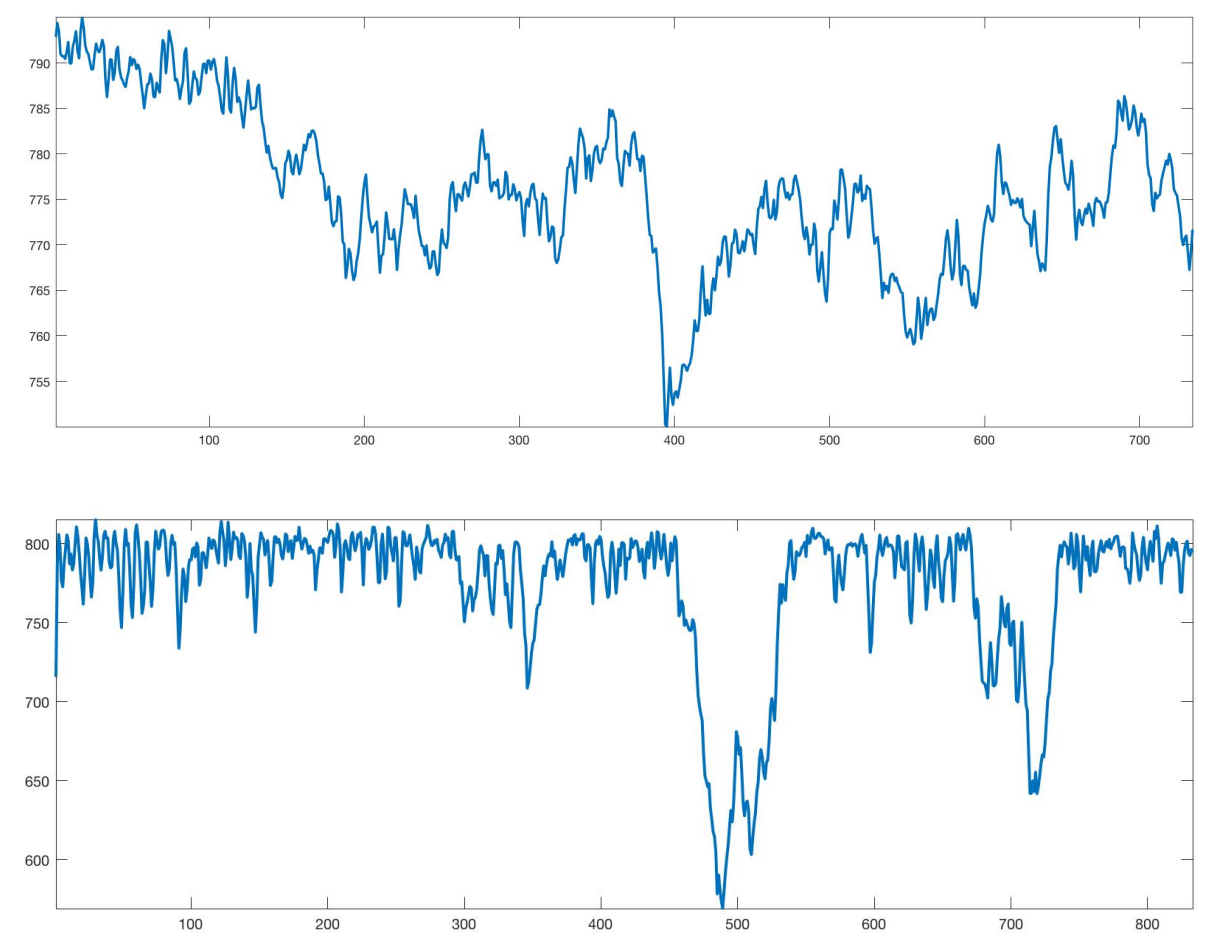

Figure 2: Production in the baseline: cross simulation mean (top); single-seed (bottom).

institutions (SIFIs): they are financial institutions whose distress, because of their size, complexity and systemic interconnectedness, causes significant disruption to the wider financial system and economic activity.

The second aspect is the strengthening of the surviving banks in the market, as their equity grows remarkably over time.

Let us now analyse the impact of the different monetary policies, as well as the introduction of the macroprudential regulations described above. We have four different scenarios: TR, $\mathrm{CH}$, Prud-E and Prud-L.

In the TR scenario, the Taylor Rule is activated and the nominal interest rate evolves endogenously as described in Equation 13. In the $\mathrm{CH}$ scenario, the central bank still operates under the Taylor Rule specified above. However, any time a long recession hits the economy, the central bank also provides households in the economy with an amount of money equal to the $0.01 \%$ of nominal GDP, until the recession stops and the economy gets back on a recovery path. This is an unconventional monetary policy of the cash-in-hands type. In the Prud-E scenario, the maximum leverage ratio of the banking system changes endogenously in order to tighten the limit on the banking borrowing capacity. The change in the maximum allowable leverage ratio is triggered by recessionary episodes. Finally, in the Prud-L scenario, the required liquidity ratio of the banking system changes endogenously in order to increase the required amount of liquidity that each commercial bank has to hold. Also in this case the change in the required liquidity ratio is triggered 

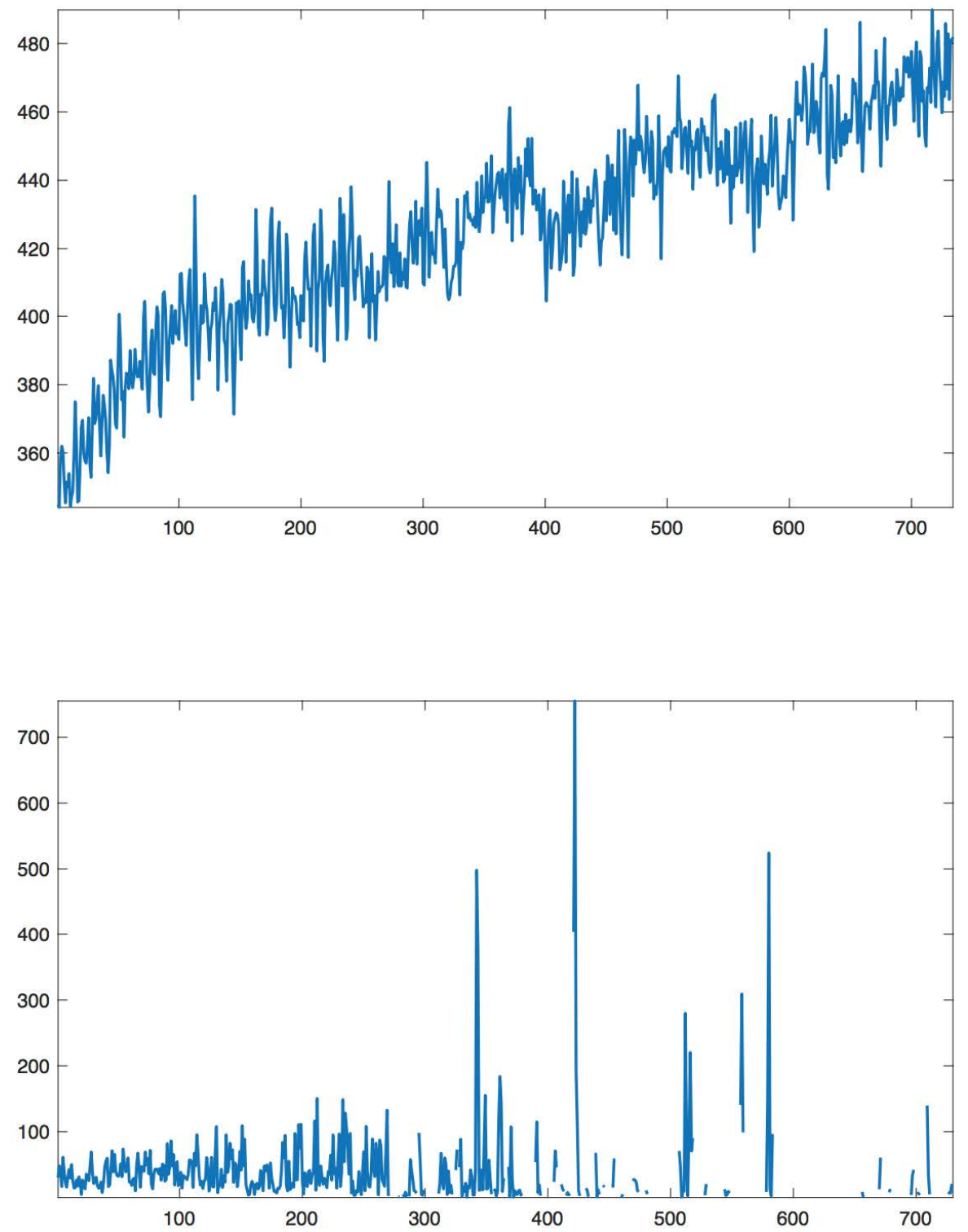

Figure 3: Total credit issued by the banking sector (top) and overall amount of loans issued in the interbank market (bottom). 


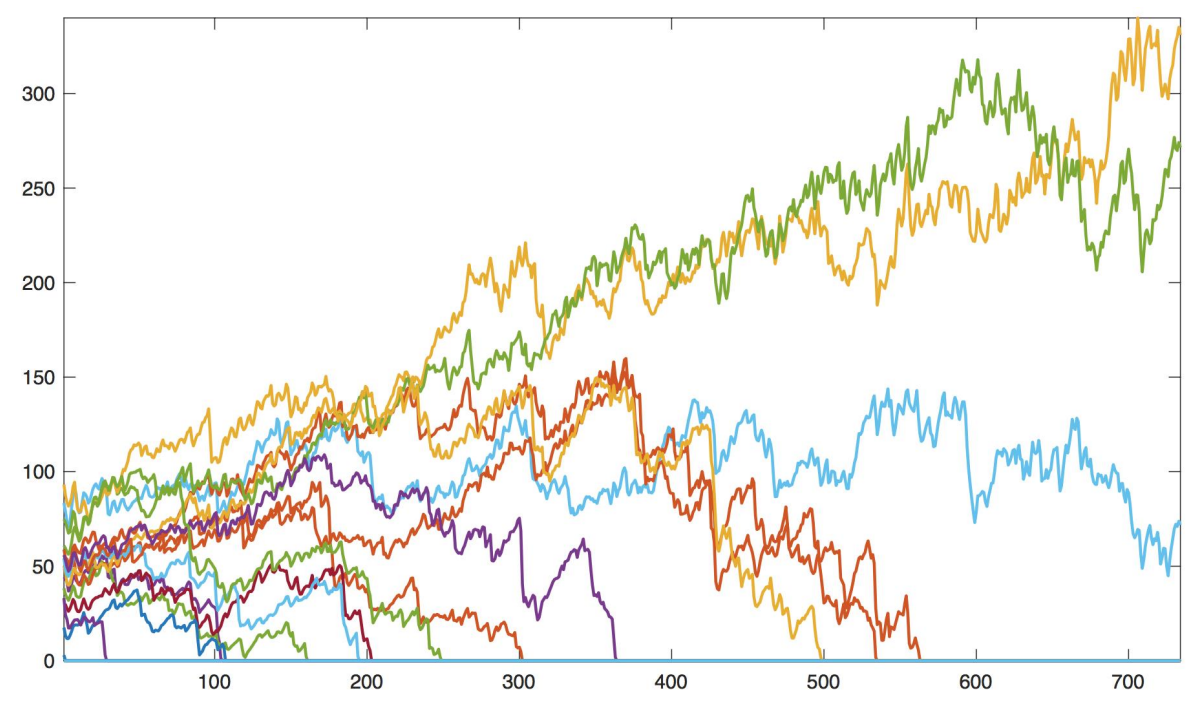

Figure 4: Total bank equity for each bank $b$.

by any recessionary event. Notice that in both Prud-E and Prud-L, the central bank still operates under the Taylor Rule.

Our analysis looks at the stability of the system from different perspectives.

A first aspect consists in the comparison of the different scenarios based on the number of bank defaults, the number of crises and the average crisis duration (in quarters). Each of these values is computed across the $50 \mathrm{MC}$ simulations. In particular, a crisis includes a recession and a recovery, where the recession is defined as any time the rate of growth is negative and production falls below its corresponding exponential moving average for more than 25 periods (corresponding roughly to 2 quarters).

These values allow to have an intuitive picture of the effectiveness of the monetary and macroprudential policies implemented in the various scenarios.

\begin{tabular}{cccc}
\hline \hline & Number of bank defaults & Number of crises & Average crisis duration \\
\hline Baseline & 16 & 4 & 12 \\
TR & 17 & 3 & 8 \\
CH & 16 & 3 & 11 \\
Prud-E & 16 & 3 & 12 \\
Prud-L & 16 & 4 & 12 \\
\hline \hline
\end{tabular}

Table 2: Scenario comparison in terms of number bank defaults, number of crises and crisis duration in quarters.

Our results suggest that the economy has a similar performance across the scenarios regarding the number of bank defaults (Table 2). However, the TR, CH and Prud-E scenarios seem to be more stable compared to the other two scenarios, as the number of economic crises amounts to 3 compared to 4 in the other cases. The major element of difference, however, can be found in the average duration of the crises: the number falls to 8 quarters in TR, while reaching 12 quarters in 

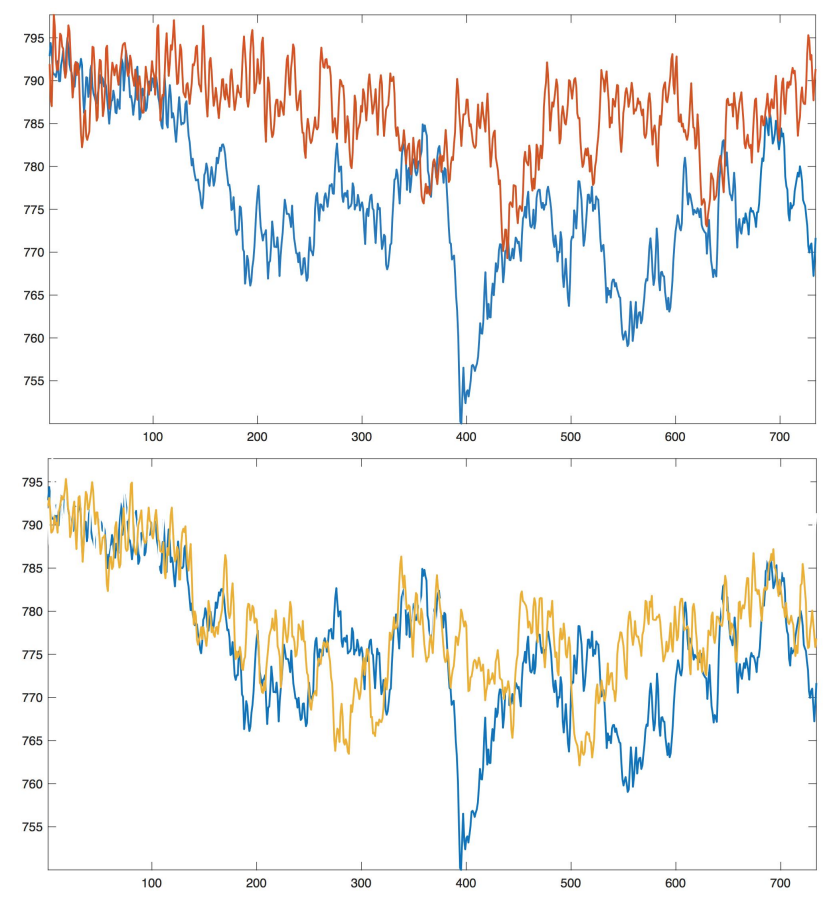

Figure 5: Production in the baseline (blue), in TR (red) and CH (yellow).

the baseline, Prud-E and Prud-L. To put it simply, it seems that the conventional monetary policy implemented via a simple Taylor Rule represents the most effective policy response in order to reduce the length of the crises in the economy. Hence, in line with Delli Gatti and Desiderio (2015), we find that the standard Taylor Rule is quite successful as an effective macro-stabilization tool. More specifically, TR represents the most stable scenario in our simulations.

\begin{tabular}{cccc}
\hline \hline & Average real GDP & Variance & Coefficient of variation \\
\hline Baseline & 777.53 & 92.96 & 0.012 \\
TR & 786.83 & 29.99 & 0.006 \\
CH & 779.91 & 64.49 & 0.011 \\
Prud-E & 778.51 & 75.86 & 0.011 \\
Prud-L & 778.52 & 79.97 & 0.011 \\
\hline \hline
\end{tabular}

Table 3: Scenario comparison in terms of GDP levels and variations.

This result is confirmed also by the analysis of the dynamics of production in the different scenarios. In particular, Figure 5 shows the time series of real GDP in the baseline compared to TR and $\mathrm{CH}$. It is possible to notice that production is, on average, higher in TR compared to $\mathrm{CH}$. Indeed, the average real GDP is 786.83 in TR and $779.91 \mathrm{in} \mathrm{CH}$, with a coefficient of variation of 0.006 and 0.011 respectively.

Table 3 also shows that the average level of real GDP in the baseline is 777.53, with a coefficient of variation of 0.012 . These values confirm the positive stabilising effect of the introduction of the 
Taylor Rule compared to the baseline and the unconventional monetary policy. Also, there seems to be no sizeable distinction between the two macroprudential policies, especially by looking at the average real GDP as well as its corresponding coefficient of variation.

\section{Conclusions}

Our paper introduces some major extensions to the macroeconomic agent-based model by Delli Gatti et al. (2011). In particular, we include an interbank market, an improved specification of the consumption function, some frictions in the labour market and a public sector with a government operating in a bonds market and a central bank. Our extensions significantly modify the main results of the original model. In particular, the interbank market has a very active role in our artificial economy. Additionally, the dynamics of the macro time series such as production and aggregate consumption show a much different pattern, characterised by minor oscillations and the presence of a major episode of crisis. Moreover, the inclusion of the public sector, and the better specification of some mechanisms in the banking sector, allow us to test different policy scenarios by means of computer simulations. In particular, we compare the implementation of a monetary policy under a standard Taylor Rule with an unconventional policy of the cash-in-hands type. Our results highlight the slightly better performance of the economy under the first type of policy, as the model shows a lower number of crisis and a shorter duration of the recessionary events. A further element of our work consists in the analysis of two macro-prudential policies implemented via a modification of the maximum allowable leverage ratio and the required liquidity ratio of the banking sector. The former seems to be more effective than the latter in terms of frequency of crises. However, no difference seems to emergence as far as the duration of the crises is concerned. In particular, the policy acting on the required liquidity ratio determines no modifications compared to our baseline scenario.

\section{References}

[1] Acharya, V. V. and Yorulmazer, T. (2008). Cash-in-the-market pricing and optimal resolution of bank failures. The Review of Financial Studies, 21(6): 2705-2742. https://doi.org/10.1093/ rfs/hhm07

[2] Adrian, T. and Shin, H.S. (2009). Money, liquidity, and monetary policy. American Economic Review, 99(2): 600-605. https://www.jstor.org/stable/25592465?seq=1\#page_scan_tab_ contents

[3] Allen, F., Carletti, E. and Gale, D. (2009). Interbank market liquidity and central bank intervention. Journal of Monetary Economics, 56(5):639-652. https://doi.org/10.1016/j.jmoneco. 2009.04.003

[4] Allen, F. and Gale, D. (2000). Financial contagion. Journal of Political Economy, 108(1): 1-33. https://www.journals.uchicago.edu/doi/10.1086/262109 
[5] Basel Committee on Banking Supervision (2011). Basel III: A global regulatory framework for more resilient banks and banking systems. Bank for International Settements. https: //www.bis.org/publ/bcbs189.pdf

[6] Christiano, L. J., Eichenbaum, M. and Evans, C. L. (2005). Nominal Rigidities and the dynamic effects of a shock to monetary policy. Journal of Political Economy, 113(1): 1-45. https://doi.org/10.1086/426038

[7] Delli Gatti, D. and Desiderio, S. (2015). Monetary policy experiments in an agent-based model with financial frictions. Journal of Economic Interaction and Coordination, 10(2): 265-286 . https://doi.org/10.1007/s11403-014-0123-7

[8] Delli Gatti, D., Desiderio, S., Gaffeo, E., Cirillo, P. and Gallegati, M. (2011). Macroeconomics from the bottom-up. Springer Science Business Media.

[9] Delli Gatti, D., Gallegati, M., Greenwald, B. C., Russo, A. and Stiglitz, J. E. (2009). Business fluctuations and bankruptcy avalanches in an evolving network economy. Journal of Economic Interaction and Coordination, 4(2): 195-212. https://doi.org/10.1007/s11403-009-0054-x

[10] Ferrari, M. (2016). Cascades along the business cycle. SSRN Electronic Journal. http: //dx.doi.org/10.2139/ssrn.2837722

[11] Financial Stability Board (2011). Policy measures to address systemically important financial institutions. Technical Report, Financial Stability Board. http://www.fsb.org/2011/11/r_ $111104 \mathrm{bb} /$

[12] Freixas, X. and Jorge, J. (2008). The role of interbank markets in monetary policy: A model with rationing. Journal of Money, Credit and Banking, 40(6): 1151-1176. https: //doi.org/10.1111/j.1538-4616.2008.00152.x

[13] Freixas, X., Martin, A., and Skeie, D. (2011). Bank liquidity, interbank markets, and monetary policy. Review of Financial Studies, 24(8): 2656-2692. https://www.jstor.org/stable/ 20869320?seq=1\#page_scan_tab_contents

[14] Friedman, M. (1969). The optimum quantity of money and other essays. Chicago: Aldine Publishing Company.

[15] Gabbi, G., Iori, G., Jafarey, S. and Porter, J. (2015). Financial regulations and bank credit to the real economy. Journal of Economic Dynamics and Control, 50: 117-143. https: //doi.org/10.1016/j.jedc.2014.07.002

[16] Gertler, M. and Karadi, P. (2011). A model of unconventional monetary policy. Journal of Monetary Economics, 58(1): 17-34. https://ideas.repec.org/a/eee/moneco/v58y2011i1p17-34. html

[17] Gualdi, S., Tarzia, M., Zamponi, F. and Bouchaud, J. P. (2017). Monetary policy and dark corners in a stylized agent-based model. Journal of Economic Interaction and Coordination, 12(3): 507-537. https://doi.org/10.1007/s11403-016-0174-z 
[18] Hanson, S. G., Kashyap, A. K. and Stein, J. C. (2011). A macroprudential approach to financial regulation. Journal of Economic Perspectives, 25(1): 3-28. https://www.aeaweb.org/ articles?id=10.1257/jep.25.1.3

[19] Heider, F., Hoerova, M. and Holthausen, C. (2015). Liquidity hoarding and interbank market rates: The role of counterparty risk. Journal of Financial Economics, 118(2): 336-354. https://doi.org/10.1016/j.jfineco.2015.07.002

[20] Iori, G., Kapar, B., and Olmo, J. (2015a). Bank characteristics and the interbank money market: A distributional approach. Studies in Nonlinear Dynamics and Econometrics, 19(3): 249-283. https://www.researchgate.net/publication/277922535_Bank_characteristics_and_the_ interbank_money_market_A_distributional_approach

[21] Iori, G., Mantegna, R. N., Marotta, L., Micciche, S., Porter, J. and Tumminello, M. (2015b). Networked relationships in the e-MID interbank market: A trading model with memory. Journal of Economic Dynamics and Control, 50: 98-116. https://doi.org/10.1016/j.jedc.2014.08.016

[22] Kiyotaki, N. and Moore, J. (2012). Liquidity, business cycles, and monetary policy. NBER Working Paper, No 17934. https://econpapers.repec.org/paper/nbrnberwo/17934.htm

[23] Krause, M. U., Lubik, T., Krause, M. U., and Lubik, T. A. (2014). Modeling labor markets in macroeconomics : Search and matching. Working paper. Available at: https: //www.richmondfed.org/publications/research/working_papers/2014/wp_14-19

[24] Michaillat, P. and Saez, E. (2014). An economical business- cycle model. NBER Working Papers, No 19777. http://www.nber.org/papers/w19777

[25] Phillips, A. (1958). The Relation between unemployment and the rate of change of money wage rates in the United Kingdom. Economica, 25(100):283-299. https://www.jstor.org/stable/ 2550759?seq=1\#page_scan_tab_contents

[26] Shin, H. S. (2011). Macroprudential policies beyond Basel III. In Shin, H. S. (2011) "Macroprudential regulation and policy". Bank for International Settlements, 60: 5-15. https: //econpapers.repec.org/bookchap/bisbisbpc/60-02.htm

[27] Smets, F. and Wouters, R. (2007). Shocks and frictions in US business cycles: A Bayesian DSGE approach. American Economic Review, 97(3): 586-606. https://www.aeaweb.org/ articles?id=10.1257/aer.97.3.586

[28] Taylor, J. B. (1993). Discretion practice versus policy rules in practice. Carnegie-Rochester Conference Series on Public Policy, 39:195-214. https://doi.org/10.1016/0167-2231(93) 90009-L

[29] Tedeschi, G., Mazloumian, A., Gallegati, M., and Helbing, D. (2012). Bankruptcy cascades in interbank markets. PLoS ONE, 7(12). https://doi.org/10.1371/journal.pone.0052749 
Economics: The Open-Access, Open-Assessment E-Journal 12 (2018-47)

[30] Xu, T., He, J. and Li, S. (2016). A dynamic network model for interbank market. Physica A:

Statistical Mechanics and its Applications, 463: 131-138. https://doi.org/10.1016/j.physa.2016. 07.013 


\section{Economics}

Please note:

You are most sincerely encouraged to participate in the open assessment of this article. You can do so by either recommending the article or by posting your comments.

Please go to:

http://www.economics-ejournal.org/economics/journalarticles/2018-47/

The Editor 